where experiments could be performed. If much of the oceanic sediment is swept down into the mantle here, as seems increasingly likely, this could have profound effects on the chemical balance of the Earth's interior.

Palaeoclimates are inextricably linked with past oceanic circulation. In particular, the Antarctic regions carry the full record of glaciation and deglaciation, as well as an amplified record of pre-glacial climates. This is a prime target for any further drilling, but others too were identified in this area, such as the history of the vertical temperature and oxygenation structure of the deep oceans, and the nature of the great Pacific Ocean of $200 \mathrm{Myr}$ ago. Only small fragments of this ocean crust remain, and these are buried deep beneath later sediments. However the Pacific then was even larger than today, and was essentially the only ocean, lying opposite the supercontinent of Pangaea.

Finally there is the problem of the origin of split continental margins, such as those bordering the Atlantic. Since these areas are closely associated with petroleum generation and might contain deep-water petroleum deposits, they are clearly worth drilling. To understand them you need to drill where oil companies will not - on margins where sediments are thin and the history is close to the surface. During last summer great advances were made in our understanding of these areas by Challenger drilling around the Bay of Biscay and Rockall Bank, and this work is to be extended.

Which would be best for all this drilling, Explorer or Challenger? The tools and techniques people presented a report which essentially said that you get what you pay for. Challenger could be upgraded in many ways at a cost of $\$ 7.5$ million, although she could not apparently be fully strengthened for work in ice. Explorer could be converted for drilling at a greater cost, but would have greater capabilities, especially if extra money was available. Some of the scientific targets, such as the bare rock drilling, would require extensive engineering development, while others could only be reached using a fully converted Explorer. An informal vote was called for among the scientists present to see the extent of the support for Explorer or Challenger, and a substantial majority felt that the potential of Explorer outweighed the know abilities (and restrictions) of Challenger.

The general view of COSOD was that oceanic drilling should be regarded as integral a part of earth science as radiotelescopes are of astronomy. Instead of the present situation, where continuation of drilling has to be fought for every two years, there should be a general expectation, as with telescopes, that.funding will continue and that the great contributions made to earth science by drilling will continue at the same or higher levels over at least the next decade.

\section{Life seen from a medieval latrine}

\author{
from Peter D. Moore
}

IF, as it is said, one can tell much about man's way of life from the contents of his garbage can, then one may indeed be able to tell even more from the contents of his latrine. It is perhaps surprising, then, that such depositories of environmental information have been rather neglected by archaeologists, despite their longestablished affinity for middens. There are exceptions, of course, such as the delvings of Pike and Biddle (Antiquity 40, 293; $1966)$ into the sewerage system of medieval Winchester in search of human gut parasites and Dennel's (Econ. Bot. 24, 151; 1970) analysis of plant macroscopic remains from a sewer in medieval Plymouth. In the New World less is known but nevertheless, Schoewetter (Archaeology of the Mammoth Cave Area, Academic Press, 1974) has been able to analyse the contents of sub-fossil human faeces in Upper Salts Cave, Arizona.

A golden opportunity to develop an interdisciplinary approach to the study of long-abandoned lavatories arose in Worcester in 1975 when the clearance of an area of housing for the development of a new road revealed the existence of the lower part of a medieval barrel latrine filled with organic material. The find was excavated by Greig and its contents analysed for beetles (Osborne), plant macrofossils and pollen parasites (Greigh), bones (Jones) and cloth (Crowfoot and Raphael). It was radiocarbon-dated to the mid fifteenth century and the work has now been reported by Greig ( $J$. archaeol. Sci. 8, 265; 1981).

The beetle fauna was dominated by Tipnus unicolor and Mycetaea hirta, which Osborne considers to be characteristic species of the cesspit habitat. He comments that the scarcity of these species today contrasts strongly with their abundance in medieval times, no doubt a consequence of such developments as the water closet. Of the other 36 beetle taxa recorded, an intriguing find is Anobium punctatum, the furniture beetle or woodworm. It may be that this hapless insect inhabited the (presumed) wooden seat above the latrine and that it died on emergence, but Osborne considers this taxon to be something of a coleopteran 'background noise' in a variety of deposits and therefore of little significance. Other beetles are characteristic of storcd grain, or vegetables, which suggests an admixture of kitchen refuse in the barrel. It is possible

Peter D. Moore is Senior Lecturer in the Department of Plant Sciences, King's College, University of London. that such material could have been used for hygienic purposes together with the fragments of cloth and moss (tentatively identified as Thuidium) also found in the barrel.

Interpretation of the wealth of plant material found in the latrine is complicated by this input of extraneous vegetable matter. Undoubtedly some of the fruits and seeds found have passed through the human gut, such as Robus fruticosus (bramble - an unlikely candidate for hygienic uses), Fragaria (strawberry), Vitis (grape) and Ficus (fig). The figs must surely have been imported but it is possible that the grapes were locally grown. Many fruits and seeds were weeds of cultivation, or hedgerow species which could have found their way into collections of straw, indeed in the case of some of these, such as fennel (Foeniculum vulgare), coriander (Coriandrum sativum) and carrot (Dancus carota), it is difficult to be sure whether their origins are cultivated or casual. Certainly some of the seeds must be derived from the contaminant weeds of medieval crops, such as the corn cockle (Agrostemma githago), all species which have declined drastically in the present century with the advent of herbicides and whose demise is greatly mourned by the pestiphile lobby among conservationists.

Anyone who reads old herbals will be aware of the degree to which our forefathers were obsessed with the activities of their alimentary systems. It is natural, therefore, to look expectantly into the contents of the latrine in hope of finding direct evidence of the use of herbs. There are indeed some seeds of such plants as self heal (Prunella vulgaris) and black nightshade (Solanum nigrum), quite apart from the fig, of course. But some of the finds may give cause for concern, such as the deadly nightshade (Atropa belladona) and water dropwort (Oenanthe croccata) and hepbane (Hyoscyamus niger). In view of the toxicity of these species, one cannot help wondering what eventually befell the user of the latrine.

A sad, though predictable, feature of the analysis is the high concentration of parasite eggs Trichuris (whip worm) and Ascaris (roundworm), with the former predominating in the ratio $3: 1$. This reflects the generally poor living conditions and lack of hygiene at that time.

From the contents of this barrel, Greig has managed to piece together an intriguing and complex picture of everyday medieval life in Worcester and may have purged some of the disinclination to exploit the archaeological potential of such residues. 